\title{
Trajetória e perspectivas do Museu de Arqueologia e Etnologia da USP (1964-2011)
}

\author{
MARIA ISABEL D'AGOSTINO FLEMING \\ e MARIA BEATRIZ BORBA FLORENZANO ${ }^{1}$
}

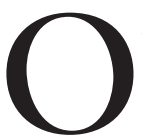
ANO DE 2010 é um marco importante na história do Museu de Arqueologia e Etnologia (MAE) da USP. Com efeito, a partir de 24 de dezembro desse ano (Resoluções n.5.900 e 5.901), o MAE, juntamente com os demais Museus estatutários da Universidade, passa a ser uma Unidade universitária autônoma, como as Faculdades, as Escolas, os Institutos. Não mais está relacionado e/ou dependente de uma única pró-reitoria, como era o caso até então, podendo atuar como as demais Unidades, escolhendo os seus caminhos e sendo representado nos Conselhos Centrais da Universidade. A partir de 2010, também ficou assegurado ao MAE - graças a diligências da atual reitoria, do Ministério Público Federal e do próprio MAE - a possibilidade de contar, a partir de 2013, com uma sede adequada a um Museu Universitário de sua envergadura: com espaços expositivos significativos; salas de aula; laboratórios de pesquisa; espaços adequados a uma biblioteca do porte da do MAE; reservas técnicas com condições de abrigar como convém o patrimônio arqueológico e etnográfico sob a sua guarda.

Não foi um caminho nem curto e nem fácil o percorrido pelo nosso $\mathrm{Mu}$ seu na Universidade. Chegar a esse ponto dependeu de muito esforço conjunto tanto de seus docentes como de seus servidores não docentes; do papel fundamental de alguns diretores da instituição; do apoio dos órgão centrais da Universidade em momentos cruciais e da indispensável união entre os quatro Museus estatutários da USP: além do MAE, o Museu de Zoologia, o Museu de Arte Contemporânea e o Museu Paulista.

A história do MAE começa na década de 1960, quando foi criado - inicialmente com o nome de Museu de Arte e Arqueologia - em 24 de julho de 1964. A criação desse museu foi o resultado do empenho de Francisco Matarazzo Sobrinho junto a representantes de entidades oficiais e museus da Itália, o que resultou na doação à Universidade de São Paulo de um valioso acervo de Arqueologia Clássica (536 peças) (Simões de Paula, 1965, p.15). Em seguida, 1965 e 


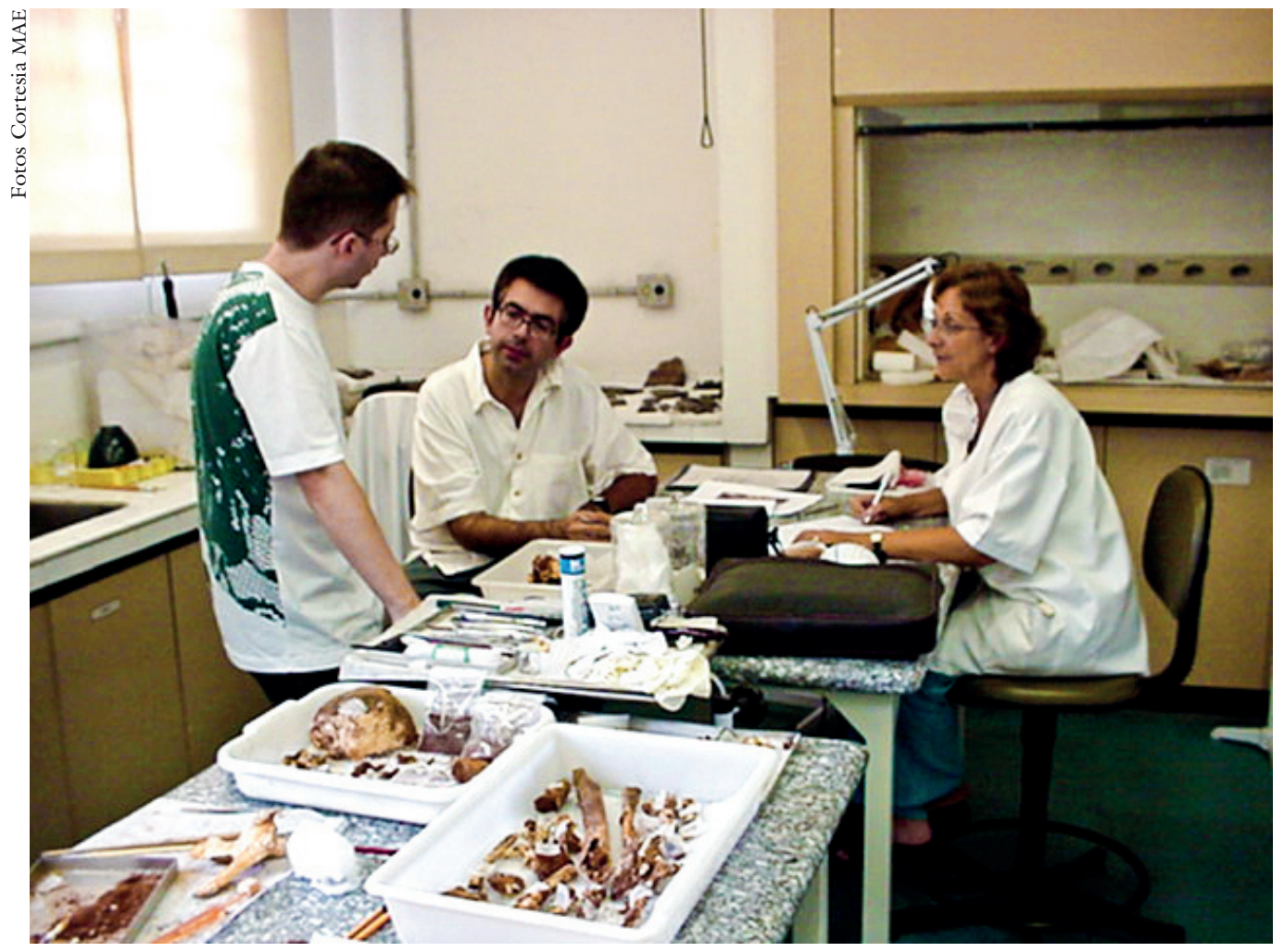

Trabalho em laboratório de pesquisa.

1966, outras doações institucionais (Museus de Nicosia, Chipre, e de Conimbriga, Portugal) (Bezerra de Meneses, 1965b, p.30) ou privadas vieram se somar a esse primeiro núcleo. Nesses anos iniciais, a necessidade de dar ao Museu uma linha de atuação que promovesse um melhor conhecimento da sociedade brasileira e que dirigisse o potencial da instituição no sentido de oferecer essa contribuição à Universidade fez que o então diretor, Prof. Ulpiano Toledo Bezerra de Meneses, articulasse os objetivos institucionais em torno de nossas três heranças: a europeia, a americana e a africana. Assim, ao núcleo inicial das coleções de Arqueologia Clássica ou Mediterrânica, por meio de compra, doações privadas ou em comodato, foram acrescidas coleções Egípcia e Médio-Oriental, coleções de Arqueologia pré-colombiana e brasileira e coleções etnográficas africanas e afrobrasileiras. As pesquisas acompanharam a ampliação do acervo, voltando-se para novas áreas: a África Negra, a América Pré-Colombiana e o Brasil. Em 1972, com a aprovação do novo Regimento Geral da USP (Decreto n.52.906 de 27 de março de 1972), o Museu passou a chamar-se Museu de Arqueologia e Etnologia, denominação que refletia a ampliação daqueles objetivos iniciais da fundação do MAA e que caracteriza até os dias de hoje a sua vocação: a formação, ampliação, preservação de coleções arqueológicas e etnográficas e, a partir delas, o desenvolvimento de atividades de pesquisa, docência e extensão de serviços à comunidade, nas áreas fundamentais para um conhecimento antropológico do 


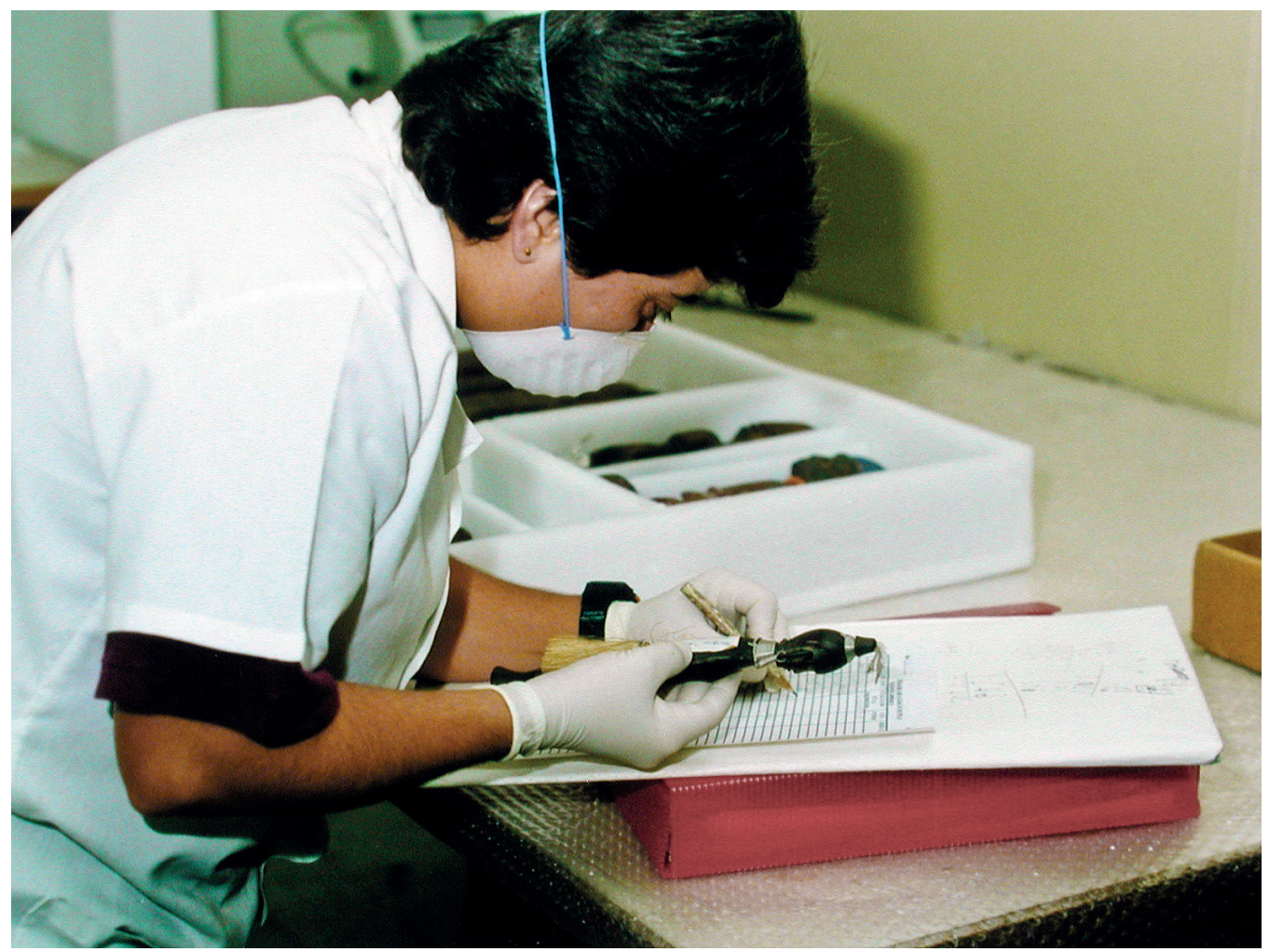

Trabalho de acondicionamento de acervo.

homem brasileiro, aprofundado por meio do estudo de suas heranças culturais. Essas vêm ainda hoje definidas como:

- Herança Mediterrânica e Médio-Oriental, entendida em seu sentido mais amplo, tendo como base a cultura greco-romana, suas raízes no Médio-Oriente - Egito e Mesopotâmia - e suas áreas de expansão;

- Herança Africana, pesquisada das culturas africanas, tendo como objetivo a compreensão e a captação da contribuição do africano na formação da cultura brasileira;

- Herança Americana, pesquisada a partir das culturas que se desenvolveram no continente americano, principalmente aquelas relacionadas com as Américas do Sul e Central. ${ }^{2}$

Para a consolidação desse projeto, o MAE realizou pesquisas de campo e de laboratório no país e no exterior, incrementando as suas coleções que hoje chegam a aproximadamente um milhão de itens de acervo.

Desde sua fundação, o MAA, e posteriormente o MAE, esteve sediado em espaços emprestados: inicialmente no edifício central da reitoria (hoje ainda conhecido como "Reitoria Velha") e depois no Prédio da História e Geografia (que hoje leva o nome do Prof. Eurípedes Simões de Paula). Em 1979, o MAE, suas coleções, biblioteca, seus docentes e funcionários foram transferidos para $\mathrm{O}$ Bloco D do Crusp, ocupando os $5^{\circ}$ e $6^{\circ}$ andares, juntamente com o Instituto de 
Pré-História $\left(3^{\circ}\right.$ e $4^{\circ}$ andares) e o Instituto de Estudos Brasileiros (térreo, $1^{\circ} \mathrm{e}$ $2^{\circ}$ andares). Na verdade, nesse momento, não foi possível, por razões técnicas, alojar a nossa volumosa biblioteca nos andares e nem trazer uma boa parte do acervo: a biblioteca foi alojada em uma das "Colmeias" da área de vivência do Conjunto Residencial da USP (Crusp) e o acervo continuou até 1998 ocupando espaços no prédio da História e Geografia, bem como uma área de reserva técnica do Departamento de Antropologia (FFLCH) que abrigava o acervo Plínio Ayrosa. Dividido, funcionando em espaços precários e não adequados a uma instituição chamada museu, o MAE continuou trabalhando, crescendo e trazendo a sua contribuição à Universidade.

Voltando aos anos iniciais do MAE, destaquemos também o lançamento em 1965 de uma revista de arte e arqueologia - Dédalo - porta-voz das pesquisas do Museu e que continuou a ser editada até 1990. Segundo o diretor responsável pela revista, o Prof. Ulpiano Bezerra de Meneses, essa tinha como programa contribuir para suscitar, desenvolver e veicular estudos sobre diversos domínios da Arqueologia e História da Arte em geral.

Dentro do contexto brasileiro, longe de fontes, carente de meios de pesquisa, prejudicado pela fase incipiente e de completa desorientação de tais disciplinas entre nós, não poderíamos pretender o grau de originalidade e profundidade que conseguem atingir publicações congêneres em outros países. Com isso não queremos significar que nosso escopo é a pura vulgarização científica. Mesmo quando êsse limite não puder ser ultrapassado - o que será, por certo, corrente - nosso esfôrço deverá tender à transformação desta Revista, antes de mais nada, num instrumento de pesquisa em nível universitário, instrumento de trabalbo, em suma. (Daí a freqüência com que trataremos de certos problemas metodológicos, como bibliografia, apresentação de museus, iniciação a áreas de pesquisa etc.). (Bezerra de Meneses, 1965a, p.9)

Outra iniciativa importantíssima que partiu do MAE no final da década de 1960 e início da década de 1970 na figura de seu diretor, o já mencionado Prof. Ulpiano, foi a criação, no bojo do Programa de Pós-Graduação em Antropologia da FFLCH, ${ }^{3}$ de duas áreas de concentração em Arqueologia: Arqueologia Brasileira e Arqueologia Mediterrânica e Médio-Oriental. Essa foi a semente de um Programa de Pós-Graduação em Arqueologia independente - como falaremos adiante - responsável pela formação de dezenas de arqueólogos que hoje atuam nos quatro cantos do Brasil. A inserção da Arqueologia na Pós-Graduação da Universidade dependeu de uma disposição em integrar vários professores que já atuavam na pesquisa e docência de Arqueologia na Universidade, mas em unidades separadas: no primeiro momento, foram assim credenciados nessas áreas de concentração professores não apenas do MAE, mas também os do Museu Paulista e do Instituto de Pré-História.

Até 1982, os quatro Museus da Universidade, definidos pelo Regimento Geral da Universidade de 1972 (Cap. III, artigo $9^{\circ}$ ) funcionavam sem Regimentos Internos, sem colegiados, sem uma estrutura legal que lhes permitisse o cresci- 
mento e a potencialização dos conhecimentos ali produzidos. Foi justamente em 8 de janeiro de 1982, pela Resolução n.2.342, ${ }^{4}$ que um Regimento para os quatro Museus foi aprovado, prevendo uma estrutura geral interna e ao menos um Conselho Administrativo que oferecesse um fórum de decisão mais ampliado e onde as metas dos Museus pudessem ser mais discutidas por seus vários setores.

A década de 1980 foi, assim, marcada no MAE por um avanço em seu estatuto legal, mas também por experimentações importantes nos seus vários setores; pela consolidação das áreas de pesquisa vinculadas aos acervos com contratação de pesquisadores; pela consolidação da pós-graduação em Arqueologia, processo que culminou em 1989 com a criação de um Programa interdepartamental, herdeiro das áreas de concentração em arqueologia do Programa de Antropologia; pela instalação de uma exposição de suas coleções no $5^{\circ}$ andar do Crusp; pelo estabelecimento de um Serviço educativo vinculado às exposições.

Em 1989, na esteira da instalação de um novo ordenamento para a Universidade com a reforma do estatuto promulgada em outubro de 1988, teve também início um movimento que buscava uma reorganização da pesquisa e das coleções arqueológicas e etnográficas da USP. Foi instaurada - por decisão da reitoria - uma Comissão, encabeçada pelo então diretor do Instituto de PréHistória, Prof. José Jobson de Andrade Arruda, que passou a considerar a possibilidade de recriar um Museu de Arqueologia e Etnologia em outro patamar. Considerava-se a "inconveniência de existirem, na Universidade de São Paulo, duplicações e superposições de Órgãos e atividades nas áreas de Arqueologia e Etnologia"; avaliava-se que "o acervo arqueológico e etnográfico da Universidade estava disperso em vários Museus e Institutos"; e que “essas dispersões e duplicidades ocorriam também no que dizia respeito às bibliotecas, equipamentos e publicações de periódicos, bem como de recursos humanos e dotações orçamentárias"; 5 e ainda que ocorria uma superposição desnecessária nas atividades de pesquisa e nos programas de trabalho, nessas áreas. Assim, naquele momento, nasceu um novo MAE por iniciativa do reitor José Goldemberg, que se baseou para tal ato no relatório da Comissão presidida pelo Prof. Jobson. Dessa feita, foram reunidos pela Resolução n.3.560, sob a denominação "Museu de Arqueologia e Etnologia”, o Instituto de Pré-História, o componente arqueológico e etnográfico do Museu Paulista, o acervo Plínio Ayrosa do Departamento de Antropologia da FFLCH e o então Museu de Arqueologia e Etnologia.

Cada uma das Instituições que foram reunidas para formar o novo MAE possuía uma importância única e uma história própria. O Museu Paulista, cuja história e acervo retrocedem até o final do século XIX e início do XX, desde a década de 1940, realizava pesquisas etnológicas e arqueológicas de ponta no Estado de São Paulo. Em 1972, havia já fundado um Centro de Arqueologia Regional em Piraju, no interior paulista, que dava o apoio ao Projeto Paranapanema (Morais, 2006). Centro esse que foi também incorporado ao novo Museu de Arqueologia e Etnologia. O acervo pré-histórico brasileiro, pré-colombiano 
e europeu do Museu Paulista trazido à nova instituição, especialmente as coleções de material lítico e cerâmico, abriu perspectivas importantes para os estudos curatoriais desse material e tem contribuído significativamente para a realização de projetos do Museu e de alunos graduandos e pós-graduandos. Pesquisadores experientes que atuavam havia muito tempo em arqueologia pré-histórica brasileira no Museu Paulista também vieram para o novo Museu. Na área de Etnologia, o Museu Paulista tinha também uma atuação muito antiga, trazendo à nova instituição não apenas os pesquisadores, como também um acervo etnográfico brasileiro valiosíssimo. No caso da incorporação ao novo MAE do Instituto de Pré-História criado por Paulo Duarte em 1962 (Decreto n.41.222 de 17 de dezembro), a nova instituição absorveu as pesquisas em sítios de grupos pescadores-coletores, caçadores-coletores e horticultores que vinham sendo realizadas na arqueologia do Estado de São Paulo e em outros Estados; pesquisas essas que haviam gerado um acervo representativo da ocupação pré-histórica regional. Também passaram a fazer parte do novo MAE um docente e um grupo ativo de jovens pesquisadores tanto na área de Arqueologia Brasileira quanto na de Museologia. Por sua vez, a coleção Plínio Ayrosa também passou a fazer parte dos acervos etnográficos do novo MAE por decisão da Resolução n.3.560. Essa coleção era preservada junto ao Departamento de Antropologia da FFLCH e agregava quatro mil itens de acervo reunidos inicialmente pelo Prof. Plínio Ayrosa, catedrático de etnografia e língua tupi-guarani, e mais tarde por meio de doações e coletas. Toda essa coleção foi somada às coleções etnográficas trazidas do Museu Paulista e àquelas do antigo MAE (Dorta \& Cury, 2000, p.26).

O nascimento do Novo MAE praticamente coincidiu com as mudanças estatutárias dos museus na Universidade: o artigo $6^{\circ}$ do Estatuto da USP de 1988 definiu como Órgãos de Integração os Museus, Institutos Especializados e Núcleos de Apoio, todos voltados para o interesse intersetorial. ${ }^{6}$ Os Órgãos de Integração tinham por meta o desenvolvimento de programas de interesse geral, bem como os propostos pelos docentes de Unidades e Departamentos relacionados com seus objetivos. A política de integração entre os museus e as unidades representantes definidas por eles, bem como o estabelecimento das normas de funcionamento e atendimento ao público caberiam à Coordenação dos Museus, presidida pelo pró-reitor de Cultura e Extensão Universitária e tendo como demais membros os diretores dos Museus e um número equivalente de Unidades de Ensino e Pesquisa afins. O Estatuto da USP também previa um Conselho Deliberativo para os museus, colegiado cuja composição seria definida em seus respectivos Regimentos.

A fusão das várias coleções arqueológicas e etnográficas da USP e dos docentes e pesquisadores em uma única instituição representou - olhando à distância - uma potencialização das possibilidades de pesquisa, de ensino e de difusão cultural. Sob a denominação Museu de Arqueologia e Etnologia, agruparam-se não apenas as coleções, mas também funcionários, pesquisadores e docentes des- 
sas instituições. O intercâmbio de experiências e o trabalho conjunto propiciaram o crescimento da Instituição e a melhor definição de seus objetivos e metas. Some-se a isso o fato de que vários dos docentes e dos pesquisadores já vinham atuando de forma integrada por meio do Programa de Pós-Graduação em Arqueologia. A exposição museográfica das coleções ganhou, e muito, em coerência e complexidade graças à união dos acervos; a biblioteca tornou-se uma grande biblioteca especializada com atendimento nacional significativo. Por sua vez, a fusão das várias instituições, incluído aí o desaparecimento institucional de uma delas (Instituto de Pré-História), impôs desafios não calculados para o corpo de servidores que passaram a trabalhar em conjunto. Desafios que diziam respeito ao funcionamento da instituição, aos métodos expositivos, à docência, à pesquisa e a tantas outras práticas com as quais cada instituição havia já se habituado.

Inicialmente, a nova instituição ficou instalada no Bloco D do Crusp, mas incorporando agora os andares que eram ocupados pelo Instituto de Pré-História. A discussão sobre um novo espaço para o MAE, que pudesse abrigar ao mesmo tempo as reservas técnicas ainda no Edifício de História e Geografia e no Departamento de Antropologia, os laboratórios de pesquisa que atendessem aos docentes e pesquisadores, o espaço expositivo que correspondesse às novas exigências museográficas, a biblioteca, passou a ser preocupação de grupos de trabalho que refletiam sobre as novas necessidades logísticas impostas pela fusão. Nesse contexto em que as necessidades criadas pela Resolução n.3.560 e os melhores caminhos para atender a elas ainda estavam em discussão, é que, em maio de 1993, o Bloco D do Crusp foi surpreendido por uma invasão estudantil movida pelo busca da recuperação das funções originais do prédio como moradia de estudantes. O MAE foi, então, de improviso, no prazo de apenas um mês, transferido para a sua atual sede no campus da capital, espaço com várias edificações, recém-desocupadas pelo Fundusp.

Apesar do trauma representado por essa mudança imprevista, completamente não planejada, para edifícios deteriorados e sem nenhuma adequação para atender a um Museu, a avaliação a posteriori demonstra que o compromisso institucional dos servidores naquele momento possibilitou, não sem enormes sacrifícios, muitas vezes pessoais, que a instituição se organizasse de sorte a continuar oferecendo sua contribuição à Universidade.

A esse esforço conjunto de compromisso institucional, devemos atribuir muitos passos importantes dados pelo MAE a partir de 1993, no sentido de se consolidar como instituição de pesquisa, docência e extensão nas áreas de arqueologia, etnologia e museologia aplicada.

$\mathrm{Na}$ área de pesquisa, é mister recordar a qualificação de vários de seus pesquisadores que ainda não possuíam o doutorado e a abertura de novas áreas de pesquisa arqueológica, etnológica, museológica. A pesquisa sobre as várias coleções, agora reunidas em um único espaço, visando à sua classificação e à sua conservação, e também à sua exposição, ganhou igualmente contornos diferen- 
ciados. A estruturação de espaços para os laboratórios foi também de grande importância para permitir a integração dos pesquisadores e dos alunos de pósgraduação que agora passavam a frequentar com maior assiduidade a instituição. Da mesma forma, a estruturação de um espaço para a biblioteca e a sua alimentação constante permitiu completar uma infraestrutura importante de pesquisa.

$\mathrm{Na}$ área de docência, um passo fundamental foi a criação da carreira docente nos Museus, conseguida em 1997 graças ao apoio que os pesquisadores obtiveram do Prof. Adilson Avansi de Abreu (então diretor do MAE) a um pleito muito antigo em todos os quatro Museus estatutários da Universidade. ${ }^{7}$ A partir de um novo Regimento (Resolução n.4.363, de 2 de abril de 1997) ${ }^{8}$ que estruturava melhor o Museu criando colegiados de decisão e setores específicos para a agilização da pesquisa, da docência e da extensão, bem como do tratamento das coleções, foi possível galgar mais um degrau no sentido de consolidar a presença do MAE na Universidade. A partir desse momento, todos os pesquisadores da casa puderam prestar concurso como docentes e, ainda, progredir na carreira, realizando os demais concursos: para livre-docência e para professor titular. $\mathrm{Na}$ área de docência, é também fundamental registrar aqui as iniciativas assumidas por alguns pesquisadores na década de 1990, junto a outros órgãos da Universidade, para possibilitar ao MAE o credenciamento de disciplinas de graduação. Como órgão de integração que era desde o Estatuto de 1988, era preciso conseguir o apoio de departamentos afins que acolhessem as nossas disciplinas e o apoio indispensável da pró-reitoria de Graduação criada também nesse estatuto. Essa tarefa dependeu de muita energia por parte de alguns pesquisadores do MAE, mas, uma vez superados os obstáculos, foi possível siglar inúmeras disciplinas optativas de graduação, criando uma grade própria e trazendo ao Museu alunos de todos os cantos da USP. Muitos esforços também - na área de docência - se concentraram em colocar e manter o Programa de Pós-graduação em Arqueologia em um patamar de reconhecimento nacional. Esforço esse que ganhou um grande incentivo a partir de $2004 \mathrm{com}$ a autonomia completa do Programa em relação à FFLCH e com a sua transferência definitiva ao MAE.

$\mathrm{Na}$ área de extensão, alimentada pelas pesquisas em Museologia aplicada, o MAE estruturou, inicialmente, uma exposição de longa duração em sua sede, inaugurada em 1995. Ao mesmo tempo, em todos esses anos, a partir de 1993, a instituição esteve envolvida em inúmeras exposições temporárias, seja no campus da capital, seja extramuros, em São Paulo ou em outras cidades pelo Brasil afora. O Serviço Educativo igualmente acompanhou a realização dessas exposições, ao lado de uma intensa programação de ações de difusão científica do conhecimento produzido no Museu e também promovendo publicações de apoio às suas atividades.

Desde 1991, o novo MAE começou a publicação institucional da Revista do Musen de Arqueologia e Etnologia (RevMAE), que substituiu os periódicos do antigo MAE, do Instituto de Pré-História e Museu Paulista (Dédalo, Revista 
de Pré-História e Revista do Museu Panlista) e cujos objetivos permaneceram a publicação de trabalhos sobre Arqueologia, Etnologia e Museologia, com ênfase em África, América, Mediterrâneo e Médio-Oriente.

Em 2005, o MAE foi designado fiel guardião das coleções de arqueologia e de etnologia do extinto Instituto Cultural Banco Santos. A chegada dessas peças ao MAE mobilizou toda a equipe de curadoria e parte da equipe docente do Museu. Foi preciso planejar a acomodação de mais de 3.500 peças, sua catalogação, classificação e sua disponibilização para pesquisadores e para a montagem de exposições. No momento em que escrevemos, tudo indica que a maioria delas serão incorporadas definitivamente aos acervos do MAE, enriquecendo-o e abrindo novas frentes de pesquisa e de divulgação de conhecimento.

A partir do século XXI, foram inúmeras as frentes em que o MAE trabalhou e continua trabalhando. Hoje temos um museu com uma pós-graduação articulada a linhas de pesquisas que abrangem todas as vocações institucionais: a arqueologia, a etnologia e a museologia aplicada. Esse Programa de Pós-Graduação é o primeiro e mais robusto centro de formação de arqueólogos do Brasil, e tem sido referência fundamental na formação de profissionais nessa área pelo menos nos últimos quinze anos. O encaminhamento de um segundo Programa de Pós-Graduação em Museologia, nesse caso, interunidades, mas com sede no MAE, já se encontra tramitando na reitoria. Nossos ex-alunos atuam em Universidades brasileiras e em instituições acadêmicas em todo o Brasil. Com relação à graduação, a discussão interna sobre a criação de um bacharelado em Arqueologia encontra-se praticamente encerrada no momento em que escrevemos e deverá em seguida ser encaminhada para avaliação às instâncias competentes na Universidade.

Com relação às atividades expositivas do riquíssimo acervo do MAE, novos projetos de reestruturação das exposições de longa duração na atual sede e na sede futura estão já bastante encaminhados. Projetos de exposições temporárias também são levados a cabo continuamente.

No tocante à pesquisa, essa vem se articulando sistematicamente em torno de laboratórios regimentais que funcionam com apoio financeiro de agências como a Fapesp e o CNPq e constituem espaços fundamentais da produção do conhecimento, congregando docentes e alunos em todos os níveis de formação em torno de temáticas comuns. Por sua vez, são vários os docentes do MAE que participam efetivamente dos núcleos de pesquisa recentemente regulamentados na Universidade, os quais promovem a interdisciplinaridade na produção do conhecimento científico. Além dos laboratórios e da participação em núcleos universitários de pesquisa, o MAE continua mantendo e incrementando o Centro de Arqueologia Ambiental Mario Neme, de Piraju, que representa hoje um posto avançado do Museu no interior de São Paulo, constituindo-se em centro importante de pesquisa e de divulgação do conhecimento no Estado, oferecendo apoio a Universidades estaduais próximas e servindo como agente difusor do 
conhecimento para as instituições de ensino secundário da região. O MAE tem tido, igualmente, uma atuação importante por meio de seus docentes em associações que reúnem pesquisadores em arqueologia e etnologia, no Brasil e no exterior. Além disso, mantemos inúmeros convênios, no Brasil e de cooperação internacional, com instituições acadêmicas, para o desenvolvimento de docência e de pesquisas. E ainda, nossos docentes de arqueologia brasileira e nossos exalunos desenvolvem projetos de pesquisa de salvamento arqueológico, que fazem parte da ação da arqueologia no processo de resgate do patrimônio arqueológico nacional ameaçado de impacto ambiental. Nesse sentido, o MAE desempenha também um papel determinante que reafirma seu perfil de instituição formadora de quadros de docentes e pesquisadores, uma vez que tais projetos têm procurado englobar pesquisas de mestrado, doutorado e iniciação científica.

Nossa infraestrutura de pesquisa e docência inclui ainda a biblioteca, especializada nas áreas de pesquisa do MAE, e que, por sua permanente atualização, sobretudo nas duas últimas décadas, atende não apenas à nossa Universidade, como também aos centros nacionais de pesquisa nas áreas de atuação do MAE.

Não é demais lembrar que a Revista do Museu de Arqueologia e Etnologia também continuou com regularidade exemplar a ser publicada anualmente desde 1991. Além disso, abriu uma série de Suplementos que abrigou publicações de monografias, anais de congressos, simpósios e outras reuniões científicas e que hoje chega ao número 10.

Hoje, pode-se considerar que o MAE, como museu universitário que é, encontra-se diante de desafios importantes no caminho dos quais a instituição poderá consolidar-se como uma verdadeira Unidade da USP. Temos agora - a partir das mudanças estatutárias e regimentais na Universidade concernentes aos Museus - a possibilidade de construir um Regimento Interno que nos permita tomar decisões de sorte a desenvolver o nosso potencial de pesquisa, de docência e de extensão universitária: sua implantação na unidade deverá incorrer em um investimento de energia importante nos próximos meses e implicará a construção de um novo organograma, de novos fluxos internos, e por último, mas não menos importante, a elaboração de um plano de metas viável para os próximos anos. Outra frente de trabalho diz respeito ao gerenciamento das novas demandas de espaço físico: dentro de aproximadamente dois anos, poderemos contar com um novo edifício que abrigará a instituição, permitindo o completo desenvolvimento de seu potencial. Será esse igualmente um grande desafio, pois demandará o planejamento da disposição das coleções para a mudança de endereço, e o planejamento, no detalhe, da ocupação e funcionamento dos novos espaços.

O MAE está otimista diante do panorama que se abre nessa nova fase, pois sabemos que, com o apoio que vimos tendo da Universidade, teremos a possibilidade de concretizar sonhos antigos daqueles criadores das várias Instituições que vieram compor o Museu de Arqueologia e Etnologia a partir de 1989. 
Notas

1 As autoras atuam no MAE desde 1970 e, portanto, estão envolvidas com a trajetória da instituição desde então. Dessa forma, este artigo não tem como não ser fruto de uma percepção pessoal do caminho percorrido pelo MAE. Ainda assim, procuramos ser o mais objetivas possível, incluindo datas, artigos consultados e legislação da Universidade.

2 Vocação representada em seu acervo e explicitada no documento de criação do novo MAE/USP em 1989, presente em inúmeros documentos como relatórios anuais institucionais, sugestão de critérios de avaliação para a Cert/USP, solicitações variadas feitas aos órgão centrais da USP, organogramas da Instituição.

3 Note-se que a pós-graduação na Universidade de São Paulo foi justamente formalizada em 1972, a partir do Regimento geral posto em prática pelo Decreto n.52.906 de 27 de março de1972. Cf. leginf.uspnet@usp.br.

4 DOE de 9 de janeiro de 1982.

5 Texto retirado da Resolução n.3.560, de 11 de agosto de 1989; cf. www.leginf.uspnet. usp.br.

6 Cf. www.leginf.uspnet.usp.br.

7 Sobre a situação dos docentes nos Museus antes de 1997, ver Brandão \& Costa (2007).

8 É preciso dizer que todos os quatro Museus estatutários tiveram seus novos regimentos nesse momento (www.leginf.uspnet.usp.br).

\section{Referências}

BEZERRA DE MENESES, U. T. Programa. Dédalo, v.I, n.1, p.9-10, 1965a. Crônica do Museu. Dédalo, v.I, n.1, p.29-31, 1965b.

BRANDÃO, C. R. F.; COSTA, C. Uma crônica da integração dos Museus estatutários à USP. Anais do Museu Paulista, v.15, n.1, p.207-311, 2007.

DORTA, S.; CURY, M. X. A plumaria indígena brasileira. São Paulo: Edusp, 2000.

MORAIS, J. L. de. Centro Regional de Arqueologia Ambiental Mario Neme. São Paulo: MAE/USP, 2006.

SIMÕES DE PAULA, E. A instalação do Museu de Arte e Arqueologia da Universidade de São Paulo. Dédalo, v.I, n.1, p.14-18, 1965.

RESUMO - Este texto pretende apresentar uma breve história do Museu de Arqueologia e Etnologia da USP, marcando alguns dos momentos mais importantes de sua trajetória na USP. Desde sua criação em 1964, passando pela estruturação de um novo projeto que unificou todas as coleções e pesquisas em arqueologia e etnologia em 1989 e chegando a 2010 com a sua independência como unidade de ensino, pesquisa e extensão no seio da Universidade.

Palavras-CHAVE: Museus Universitários, Pesquisa e ensino em Museus, História da USP. 
ABSTRACT - The intention of this paper is to present a brief history of the Museum of Archaeology and Ethnology of the University of São Paulo. Our aim is to register some of the most important moments of this Museum, since its creation back in 1964 down to 2010 moment when it achieved it's administrative and academic autonomy among all the other Schools, Institutes and Faculties of the University.

KEYWORDS: University Museums, Research and teaching in Museums, History of USP.

Maria Isabel D’Agostino Fleming (@ - mabelfleming@gmail.com) e Maria Beatriz Borba Florenzano (@ - florenza@usp.br) atuam no MAE desde 1970.

Recebido em 15.8.2011 e aceito em 19.8.2011. 